\title{
Analytical Network Process (ANP) to Recommend an Ice Cream to a Diabetic Patient
}

\author{
Suhas M. Gaikwad \\ Symbiosis Institute of \\ Technology (SIT), Pune \\ Affiliated to Symbiosis \\ International University (SIU), \\ Pune
}

\author{
Rahul R. Joshi \\ Symbiosis Institute of \\ Technology (SIT), Pune \\ Affiliated to Symbiosis \\ International University (SIU), \\ Pune
}

\author{
Preeti Mulay, PhD \\ Symbiosis Institute of \\ Technology (SIT), Pune \\ Affiliated to Symbiosis \\ International University (SIU), \\ Pune
}

\begin{abstract}
In this paper, the purpose of using Analytical Network Process (ANP) as a mathematical tool is to structure a multiple criterion problem by using a feedback connection control loop in order to recommend a particular ice cream to the patient suffering from diabetes. Here, results of ANP are verified by considering different weights, ratios and also, by using MATLAB for the problem under consideration.
\end{abstract}

\section{Keywords}

Analytical Network Process (ANP), Super Decision (SD) model, Partial differential equation, Ice cream attribute, Diabetic patient, MATLAB etc.

\section{INTRODUCTION}

The ANP is decision finding method and generalization of Analytical Hierarchy Process (AHP). The ANP allows feedback connection and loops [1, 3, and 5]. It is used as a technique for organizing and analyzing complex problems by using mathematics and psychology. It can use both prejudiced individual judgments and objective assessment just by considering Eigen vector and examining the reliability of the assessment by Eigen value. The combinations of individual performance indicator with one of key performance indicator are done in order to assign a different weight to each criterion or attribute [7, 8, and 10]. The process of ANP is mainly used to calculate weights. It considers ratios for paired comparison. The inputs for ANP are alternatives and criterions. In this paper, four different types of ice cream viz., Breyers butter almond, Breyers peanut butter and fudge; Breyers extra creamy chocolate, Ben and jerry coffee are considered as four different alternatives $[6,9]$. The criterions considered for ice cream are Sugar, Calories, Cholesterol and Proteins which are attributes of an ice cream. This paper proposes a method for recommending a particular ice cream to a diabetic patient by developing a model based on ANP [11]. The organization of this paper is viz., section 1 gives introductory details, section 2 and 3 gives details about the used methodology for analyzing problem under consideration, section 4 shows results for proposed analysis, section 5 contains conclusions, section 6 throws light on future work of this analysis and at the last in section 7 references used in this paper are listed.

\section{PARTIAL DIFFERENTIAL EQUATION MAPPING FOR ICE CREAM AND DIABETIC PATIENT}

Consider the set of partial equations as given below:

$$
\begin{array}{lc}
\frac{A * d^{2} u}{d x^{2}}+B \frac{d^{2} u}{d x^{1} \mathrm{dy}^{1}}+c \frac{d^{2} u}{d x^{2}} & +D=0 \\
B^{2}-4 * A * C=0 & ---[1] \\
\text { As } B^{2}-4 * A * C<0 & \text {-------- [2] } \\
B^{2}-4 * A * C=0 & \text { Parabolic equation } \\
B^{2}-4 * A * C>0 & \text { Hyperbolic equation }
\end{array}
$$

Use these partial differential equations for the problem under consideration taking into account sugar as an impactful attribute. The considered four different ice creams have sugar content values as given below:

$\mathrm{A}=13, \mathrm{~B}=19, \mathrm{C}=26, \mathrm{D}=27$

Substituting above values in equation [2]

$B^{2}-4 * \mathrm{~A} * \mathrm{C}<0 \quad------$ Elliptical equation for ice cream

Now, consider diabetic patient dataset for sugar level

$\mathrm{A}=262, \mathrm{~B}=232, \mathrm{C}=88, \mathrm{D}=77$.

Substituting above values in equation [2]

$B^{2}-4 * \mathrm{~A} * \mathrm{C}<0 \quad$ - Elliptical equation for diabetic patient

As both the equation that is for ice cream and diabetic patient are in elliptical form so mapping of both equations can be achieved.

\section{METHODOLOGY USED FOR CLUSTER NODE AND FEEDBACK LOOP MAPPING}

The first step while developing a ANP model for a particular problem is to arrange its details in hierarchy which are shown in figure 1, it also shows objective of this analysis which is to recommend a particular ice cream to a diabetic patient. The next level shows different criterions cum attributes of an ice cream which are Sugar, Calories, Cholesterol and proteins. The last level i.e. level 2 shows different types of ice cream like Breyers butter almond, Breyers peanut butter and fudge, Breyers extra creamy chocolate and Ben and jerry coffee are considered. Here, details of patient are not considered as a criterion because by untying those from details of ice cream study among them can be carried out straightforwardly. The 
hierarchical levels for analyzing details about ice cream in terms of Analytical Network Process Super Decision Model (ANPSD) are shown in figure 1. The details about cluster nodes and feedback loop are in figure 2. Also, comparison of alternatives and assigning weight is shown in figure 3 . The super matrix is given in table 1 and the results are generated where alternatives are Breyers butter almond (B.b), Breyers peanut butter and fudge (B.p), Breyers extra creamy chocolate (B.e.), Ben and jerry coffee (B.j) and criterions are Sugar (S.g), Calories (C.l), Cholesterol (Ch) and proteins (Pr).

\section{RESULTS}

The highest Eigen vector value or weight for criterion is sugar which is $20 \%$ followed by calories which is $13 \%$ then cholesterol and finally for protein the weight is $6 \%$. Now, similarly for the alternatives the highest Eigen vector value is for Breyers butter almond (B.b) which is $28 \%$ followed by Breyers peanut butter and fudge (B.p) which is $13.4 \%$ then Ben and jerry coffee (B.j) which is $13.1 \%$ and finally Breyers extra creamy chocolate (B.e.) which is $2.7 \%$ with respect to the goal. According to assumption made in section 2 a graph for diabetic patient as a function for given ice cream can be drawn and the results for the same are shown in figure 4 .

The diabetic patients have $262 \mathrm{mg} / \mathrm{dl}, 236 \mathrm{mg} / \mathrm{dl}, 88 \mathrm{mg} / \mathrm{dl}$ and $77 \mathrm{mg} / \mathrm{dl}$ sugar levels and their weight are $55.78 \%, 26.335 \%$, $22.75 \%$ and $12.18 \%$ respectively.

The mapping between ice cream and diabetic patient is shown in figure 4 .

The diabetic patient whose sugar levels are $262 \mathrm{mg} / \mathrm{dl}, 236$ $\mathrm{mg} / \mathrm{dl}, 88 \mathrm{mg} / \mathrm{dl}$ and $77 \mathrm{mg} / \mathrm{dl}$ have weight $55.78 \%, 26.335 \%$,
$22.75 \%$ and $12.18 \%$ respectively and these values are mapped with the considered ice creams. This means that the weights for the alternatives according to Eigen value is for Breyers butter almond which is $28 \%$ followed by Breyers peanut butter and fudge having $13.4 \%$ then Ben and jerry coffee having $13.1 \%$ and lastly Breyers extra creamy chocolate having $2.7 \%$. In this way, mapping of ice cream with diabetic patient is done and results of their mapping are shown as an output in figure 4 obtained through MATLAB by considering ANPSD model.

\section{CONCLUSIONS}

The obtained result shows that with the proper usage of ANP a particular ice cream to the diabetic patient can be done. The results obtained through ANP are also are verified through MATLAB which shows that patient having a high sugar level of $262 \mathrm{mg} / \mathrm{dl}$ can consume an ice cream with lower sugar content ice cream which is Breyers butter almond, also patient with low sugar level of $77 \mathrm{mg} / \mathrm{dl}$ can consume ice cream with high sugar content which is Breyers extra creamy chocolate This paper does verification of results for proposed analysis through ANPSD model, through MATLAB and they are found to be analogues to each other.

\section{FUTURE WORK}

The obtained results from ANP model for the problem under consideration can also be compared with clusters of ice cream and with the clusters for diabetic patients in order to achieve precise validations and verifications to predict suitability of a particular ice cream for a diabetic patient.

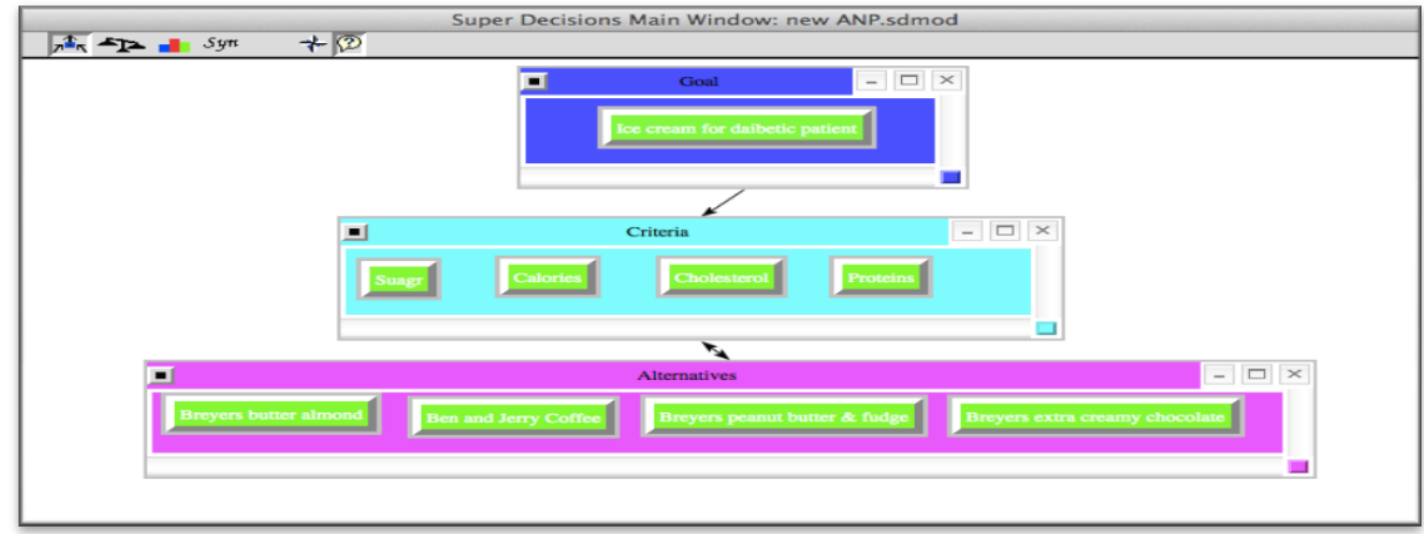

Figure 1: Hierarchical levels for analyzing details about ice cream by using ANPSD Model

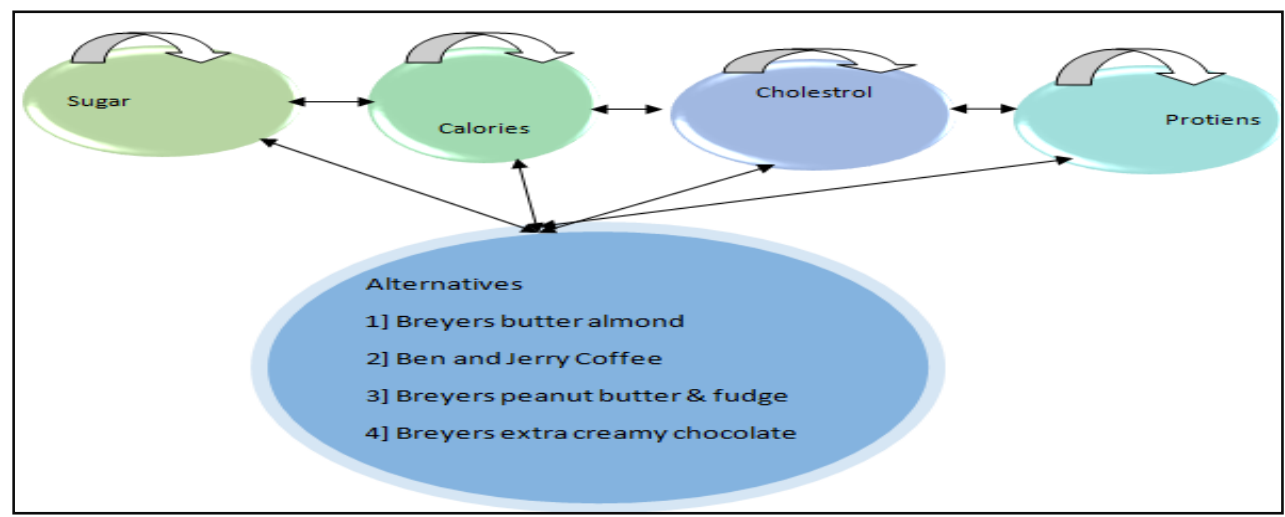

Figure 2: Cluster Nodes and Feedback Loop 


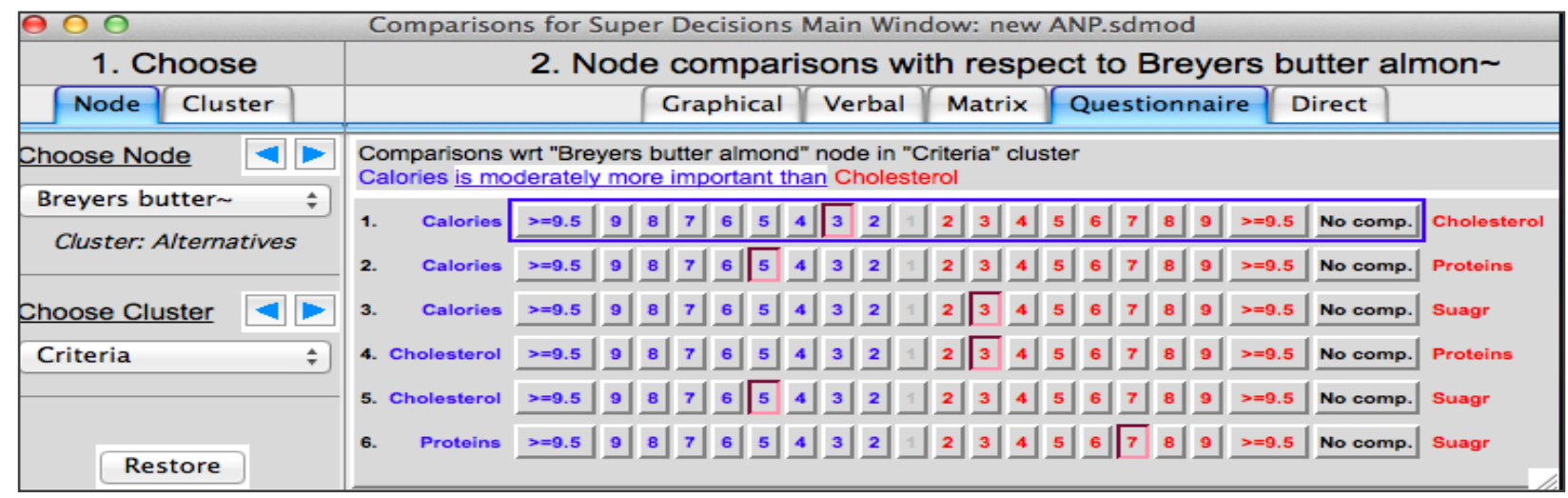

Figure 3: Assigning Weight and Comparisons in SD model

Table 1: Super Matrix

\begin{tabular}{|c|c|c|c|c|c|c|c|c|c|c|}
\hline \multicolumn{2}{|c|}{ Cluster Node Label } & \multicolumn{4}{|c|}{ Alternatives } & \multicolumn{4}{|c|}{ Criteria } & \multirow{2}{*}{$\begin{array}{l}\text { Goal } \\
\text { I.c. for } \\
\text { D.P. }\end{array}$} \\
\hline \multirow[t]{5}{*}{ Alternatives } & & B.j. & B.b & B.e. & B.p. & $\mathrm{Cl}$ & $\mathrm{Ch}$ & $\operatorname{Pr}$ & $\mathrm{Sg}$ & \\
\hline & B.j. & 0.1311 & 0.1311 & 0.1311 & 0.1311 & 0.1311 & 0.1311 & 0.1311 & 0.1311 & 0.1311 \\
\hline & B.b. & 0.2825 & 0.2825 & 0.2825 & 0.2825 & 0.2825 & 0.2825 & 0.2825 & 0.2825 & 0.2825 \\
\hline & B.e & 0.0276 & 0.0276 & 0.0276 & 0.0276 & 0.0276 & 0.0276 & 0.0276 & 0.0276 & 0.0276 \\
\hline & B.p. & 0.0587 & 0.0587 & 0.0587 & 0.0587 & 0.0587 & 0.0587 & 0.0587 & 0.0587 & 0.0587 \\
\hline \multirow{4}{*}{ Criteria } & $\mathrm{Cl}$ & 0.1342 & 0.1342 & 0.1342 & 0.1342 & 0.1342 & 0.1342 & 0.1342 & 0.1342 & 0.1342 \\
\hline & $\mathrm{Ch}$ & 0.0964 & 0.0964 & 0.0964 & 0.0964 & 0.0964 & 0.0964 & 0.0964 & 0.0964 & 0.0964 \\
\hline & $\mathrm{Pr}$ & 0.0601 & 0.0601 & 0.0601 & 0.0601 & 0.0601 & 0.0601 & 0.0601 & 0.0601 & 0.0601 \\
\hline & $\mathrm{Sg}$ & 0.2091 & 0.2091 & 0.2091 & 0.2091 & 0.2091 & 0.2091 & 0.2091 & 0.2091 & 0.2091 \\
\hline
\end{tabular}

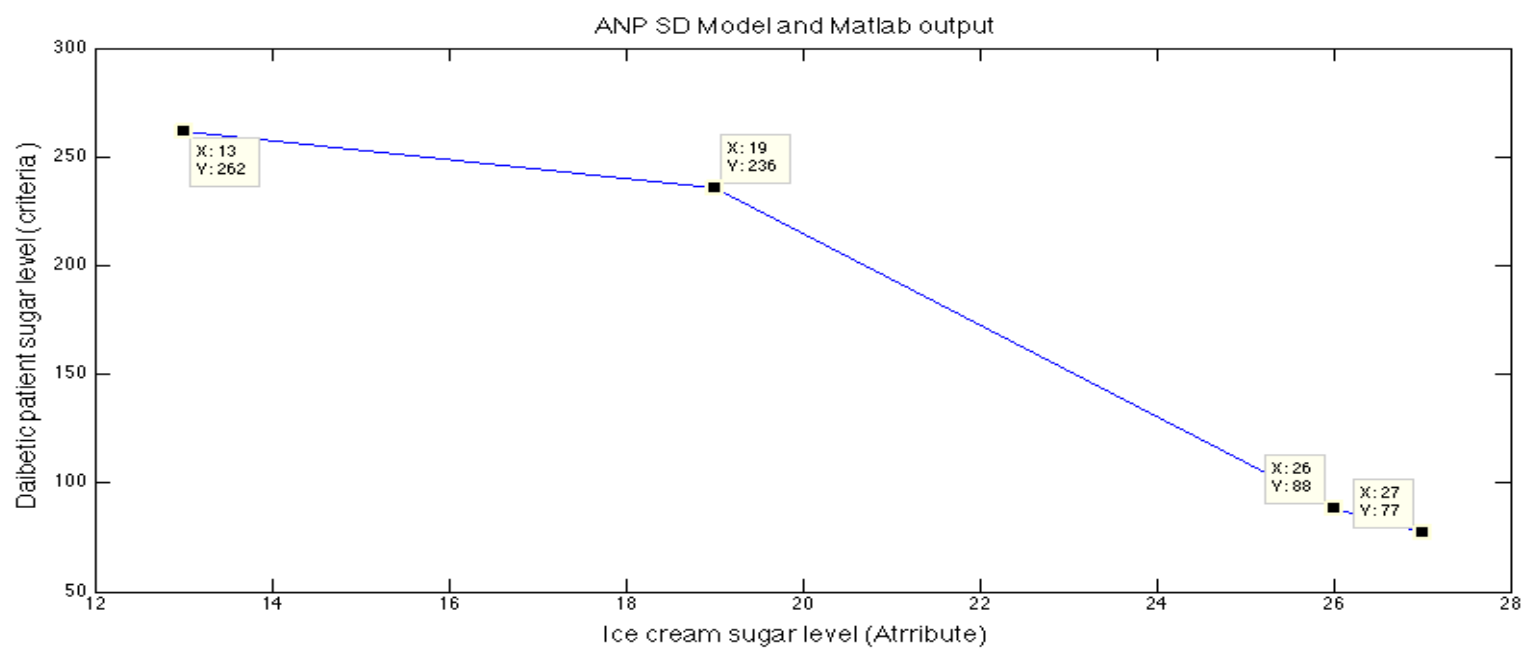

Figure 4: ANPSD Model and MATLAB results for mapping of a diabetic patient's sugar level with sugar content in the ice cream 


\section{REFERENCES}

[1] M. Hasanzadeh and A. Danehkar, "Environmental site selection for oil jetty using the analytical network process method case study: Boushehr, Iran," Ocean Engineering, vol. 77, pp. 55-60, 2014.

[2] D. Carlucci and G. Schiuma, "Applying the analytic network process to disclose knowledge assets value creation dynamics," Expert Systems with Applications, vol. 36, pp. 7687-7694, 2009.

[3] K. Kirytopoulos, D. Voulgaridou, A. Platis, and V. Leopoulos, "An effective Markov based approach for calculating the Limit Matrix in the analytic network process," European Journal of Operational Research, vol. 214, pp. 85-90, 2011.

[4] G. Kumar and J. Maiti, "Modeling risk based maintenance using fuzzy analytic network process," Expert Systems with Applications, vol. 39, pp. 9946-9954, 2012.

[5] L.A. Vidal, F. Marle, and J.C. Bocquet, "Using a Delphi process and the Analytic Hierarchy Process (AHP) to evaluate the complexity of projects," Expert Systems with Applications, vol. 38, pp. 5388-5405, 2011.

[6] S. Wibowo and H. Deng, "Intelligent decision support for effectively evaluating and selecting ships under uncertainty in marine transportation," Expert Systems with Applications, vol. 39, pp. 6911-6920, 2012.

[7] I. Yüksel and M. Dag deviren, "Using the analytic network process (ANP) in a SWOT analysis - A case study for a textile firm," Information Sciences, vol. 177, pp. 33643382, 2007

[8] A. Zouggari and L. Benyoucef, "Simulation based fuzzy TOPSIS approach for group multi-criteria supplier selection problem," Engineering Applications of Artificial Intelligence, vol. 25, pp. 507-519, 2012.

[9] B. Chang, C. Kuo, C.-H. Wu, and G.-H. Tzeng, "Using Fuzzy Analytic Network Process to assess the risks in enterprise resource planning system implementation," Applied Soft Computing, vol. 28, pp. 196-207, 2015.

[10] J. R. Yu and W.-Y. Shing, "Fuzzy analytic hierarchy process and analytic network process: An integrated fuzzy logarithmic preference programming," Applied Soft Computing, vol. 13, pp. 1792-1799, 2013

[11] Gaikwad, Suhas Machhindra, Preeti Mulay, and Rahul Raghvendra Joshi. "Analytical Hierarchy Process to Recommend an Ice Cream to a Diabetic Patient Based on Sugar Content in it." Procedia Computer Science 50 (2015): 64-72.

[12] Gaikwad, Suhas Machhindra, Preeti Mulay, and Rahul Raghvendra Joshi. "Attribute Visualization and Cluster Mapping With The Help of New Proposed Algorithm and Modified Cluster Formation Algorithm To Recommend An Ice Cream To The Diabetic Patient Based on Sugar Contain In It." International Journal of Applied Engineering Research 10.8 (2015). 